\title{
NEW ADVANCED TECHNOLOGY DEVICES FOR OPERATIONAL OCEANOGRAPHY IN EXTREME CONDITIONS
}

\author{
G. ZAPPALÀ ${ }^{1}$, G. BRUZZONE ${ }^{2}$, M. AZZARO ${ }^{1} \&$ G. CARUSO ${ }^{1}$ \\ ${ }^{1}$ Istituto per l'Ambiente Marino Costiero (IAMC), National Research Council, Messina, Italy. \\ ${ }^{2}$ Istituto di Studi sui Sistemi Intelligenti per l'Automazione (ISSIA), National Research Council, Genova, Italy.
}

\begin{abstract}
Monitoring the quality of marine ecosystems is a challenge to achieve and preserve their good environmental status. Real time or near real time acquisition and collection of physical, chemical and biological data series describing the health conditions of marine environments is needed not only when pollution episodes occur, to set up proper remediation measures, but also to follow natural variability of water quality occurring at different time scales.

The development of advanced systems for environmental monitoring (coastal and offshore buoys and platforms, unmanned or remotely controlled submersible and unsubmersible vehicles, etc.) gave a great contribution to operational oceanography, helping to bypass the limitations and costs of traditional oceanographic surveys.

The systems here described constitute an improvement and application of the know-how acquired in the last two decades in the field of advanced systems for environmental investigations. Potential advantages of the new developed system in comparison with previous prototypes are described. A wide range of applications is possible, covering the cases when conventional 'manual' sampling is not possible, or dangerous, for example in proximity to glaciers, or when oil spill, toxic algal blooms, waste water must be sampled. As a first test, the developed system has been used in Arctic waters (Svalbard Islands) to evaluate spatial variations in the microbial assemblage.

Results obtained indicate that the developed automatic vehicle and water multisampler are a good complement of traditional oceanographic cruises, and constitute a practical low-cost system to obtain data with good spatio-temporal resolution both for the initial characterization and for the study of possible natural or anthropogenic disturbance in water quality.

Keywords: advanced systems, automatic multisampler, autonomous vehicle Shark, extreme conditions.
\end{abstract}

\section{INTRODUCTION}

Marine ecosystems are amongst the most vulnerable areas to several kinds of anthropogenic pressures, most of which result in pollution, eutrophication, global warming, introduction of allochthonous species, ocean acidification. Monitoring the quality of marine ecosystems is a challenge to achieve and preserve their good environmental status. In this context, the set up of a network of observational systems is the first step for environmental monitoring. Real time or near real time acquisition and collection of physical, chemical and biological data series describing the health conditions of marine environments is needed not only when pollution episodes occur, to set up proper remediation measures, but also to follow natural variability of water quality occurring at different time scales.

A number of advanced systems have recently been developed for environmental monitoring (coastal and offshore buoys and platforms, unmanned or remotely controlled submersible 
and unsubmersible vehicles, etc..), which have given a great contribution to operational oceanography, helping to bypass the limitations and costs of traditional oceanographic surveys. The development of strategies and devices allowing the selection of representative samples is the main focus of research dealing with environmental monitoring. Indeed, automation in the sampling and analytical phases is a challenge for future development in environmental assessment. The sampling strategy must be optimized in order to satisfy research goals in terms of sampling frequency, personnel, and laboratory constraints and overall budget. Generally, collection of discrete samples is the most frequent method of sampling. However, it can only provide a snapshot of the composition of the sample at the time of sampling, which may be scarcely representative of the quality status of the environment when this is subject to a high spatial and/or temporal variability. In this sense, the use of automatic samplers may increase the sampling frequency and thus overcome some of the problems associated with discrete samples collection. Particularly, the development of an automatic multisampler proved to provide a useful tool to obtain time-series data on the status of the environment [1,2], allowing to follow temporal changes in the distribution of planktonic communities and to detect variations occurring in the water quality. Advanced technologies for marine monitoring are needed to monitor environmental changes, especially those related to ice melting. The well-known impact of global warming on the northern polar region has given rise to monitoring programs in Arctic ecosystems. To operate in extreme cold environments, particular care must be devoted to the structural adaptation of the technical equipments.

Within the rewarding Project 'Arca' coordinated by the Italian National Research Council, an equipment able to perform discrete sampling of waters in extreme conditions has been specifically designed and built to be applied in the proximity of the Kronebreen glacier in the Kongsfjorden - Svalbard Islands. The water sampler was towed up to the glacier by means of the Shark USSV (Unmanned Semi Submersible Vehicle) developed and operated by ISSIAGenova Robotics Group. This vehicle was needed to avoid exposing operators to risks caused by falling ice blocks. This paper describes the development and 'in situ' application of a first prototype of this automatic equipment showing the first results of further bacteriological analyses performed to study the abundance and metabolism of the microbial community inhabiting the waters of a polar region.

\section{MATERIALS AND METHODS}

The system developed in this study assembles together the Shark unmanned vehicle and the Automatic Multisampler, which is fully autonomous and commanded by its core electronic.

\subsection{Shark USSV (unmanned semi submersible vehicle)}

To collect samples in the stretch of sea near the Kronebreen glacier the Shark USSV towing the automatic multisampler was used. The marine robotic vehicle is $0.9 \mathrm{~m}$ long, $0.75 \mathrm{~m}$ wide, it has a height of $0.8 \mathrm{~m}$ and weighs about $45 \mathrm{~kg}$. Its thrust is provided by four DC brushless motors coupled with 4-bladed propellers, capable of a maximum bollard pull of about $15 \mathrm{~kg}$. The frame of the robot is composed of stainless steel profiles and it supports the four thrusters, two PVC cylindrical canisters and a closed-cell foam cap used to make the vehicle slightly positively buoyant. A centrally-mounted cylindrical canister contains all the computation and sensory electronic devices. In particular, Shark is equipped with a PC/104 SBC (Single Board Computer) with analog, digital and serial I/O boards mounted on its bus stack. 
The SBC is running a GNU/Linux-based operating system (Ubuntu 12.04 server) and a realtime control software application. Inside this canister there are also a GPS sensor providing the absolute position fix, an AHRS (Attitude and Heading Reference System) sensor, the servo controllers for the four thruster electrical motors and a few DC/DC converters providing the required electrical voltages. A second canister, located below the first one, contains a set of Lithium ions batteries and furnishes energy to the vehicle for a couple of hours of operations. A communication system, based on a couple of $900 \mathrm{MHz}$ Wi-Fi radios, provides a low speed (300 kbps maximum) Ethernet link between the robot and its control station. The Wi-Fi radio and GPS antennas are mounted on a small mast located on the top part of the vehicle. The control software running on the robot, written in $\mathrm{C}++$, is composed of a set of parallel threads processing control algorithms, managing sensors and actuators. The command console is composed of a rugged laptop and an external high brightness sunlight readable monitor connected to it. The laptop runs a GNU/Linux-based operating system (Ubuntu 12.04 desktop) and a HCI (Human Computer Interface) software application, written in $\mathrm{C}++$, which allows the user to send commands to the vehicle and to receive and visualise in real-time its telemetry (plant status, sensors data, etc.). The external monitor is used for displaying the video captured by a camera mounted aboard the vehicle. The vehicle pilot can interact with the HCI software either via commands entered with keyboard and mouse or by means of a joypad. Like all marine vehicles developed by CNR-ISSIA - Genoa Robotics Group [3, 4], Shark is equipped with a sophisticated control system that offers to the pilot various working modes (manual, semi-automatic and automatic) and can be remotely controlled by means of a control station (command console). Actually, because of the very difficult operating conditions of the sea near the glacier (presence of manifold small and medium size drifting icebergs) the vehicle was piloted by an human operator using the semiautomatic working mode (auto-heading and auto-speed).

The floating ice block obstacles were avoided with the help of a visual feedback, transmitted through the Wi-Fi channel, coming from an Ethernet camera mounted on the bow of Shark. During the operations at sea the USSV was connected by means of a rope to a little catamaran carrying the automatic sampler (Fig. 1). A serial RS-232 communication link was provided between the robotic vehicle and the sampler. This link, which was bridged through the Wi-Fi communication channel of Shark, made it possible for the operator to send commands to the sampler and to remotely start water sampling in the chosen points of interest.

\subsection{Automatic multisampler}

On the basis of the know-how acquired by the IAMC-Messina in the last decades, a new automatic multisampler device has been designed and built.

Automated samplers, which are usually commercially available, are characterized by some basic components, such as a programmable operation and memory device, a sample collection pump, sample bottles and a water level recorder.

Design goals were the ability to work in the severe Arctic conditions, reduced weight and size to be hosted on the ISSIA's vessel, self-contained control electronics, low power consumption.

Taking into account the short time between the sample collection and analysis and the low temperature, it has been decided to work on the fresh sample, so making it unnecessary to add a fixative as in previous versions of the multisamplers $[1,2]$ and avoiding the use of discharge closing electrovalves. 




Figure 1: The Shark (right) towing the multisampler.
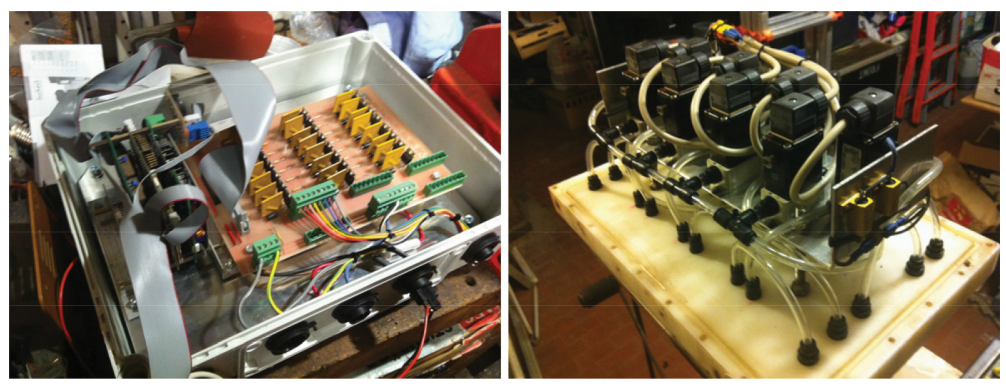

Figure 2: The control electronics (left) and the manifold with electrovalves (right).

Basically, the water sampler consists in an hydraulic and in an electronic section (Fig. 2).

\subsubsection{The hydraulic section}

A machined board hosts eight $250 \mathrm{~mL}$ sampling bottles with a free flow drainage, which are filled using a manifold of eight $2 / 2$ normally closed Burkert electro-valves with EPDM sealing membranes, able to work at $-30^{\circ} \mathrm{C}$, mounted on an electrically heated aluminium plate.

To avoid icing in the pipes, a continuous water flux is provided by a $12 \mathrm{~V}$ centrifuge pump.

A needle valve at the end of the circuit maintains the right pressure to open the electrovalves filling the bottles.

\subsubsection{The electronic section}

Both the electronics and the control software are new customized versions of those used in the past to control the SAM and PITAGEM projects coastal monitoring buoys [5-8], 
the Civitavecchia Buoy [9], the MFSTEP project automatic launcher for expendable probes [10-12].

Hosted in an IP67 box, the control computer is based on PC104 boards, assembling serial communication ports and digital I/O ports. The power interface connecting the digital I/O ports to the electrovalves is based upon PROFETs, low cost electronic devices able to switch currents of several ampere, integrating protection from short circuits, overloads and ESD with a status sensing circuit acting as a feedback to the control computer. A serial port connected to the Shark electronics enables to remotely control the operations and to receive GPS data.

To avoid moisture, the box is electrically heated.

\subsubsection{The software}

The software is written in Microsoft compiled BASIC with some routines in Assembly and runs in a DOS 6.22 environment.

An endless loop is run, waiting for the arrival of a command from the above-mentioned serial port or of a pre-programmed event.

Commands include system diagnostic commands, data acquisition commands, GPS read commands and customized commands depending on the connected devices.

Command sequences can be easily written and remotely reprogrammed without stopping normal operations $[13,14]$. Water samples can be collected both using real time commands, timed sequences or when reaching a pre-programmed GPS position

\subsection{Sampling and analytical methods}

During June 2015, surface water samples were collected by the automatic multisampler along a transect from open sea to the glacier. The samples were recovered aseptically from the system and treated to assess the bacterial abundance and metabolism. For the determination of the viable heterotrophic psychrophilic bacteria, water volumes of 100 microliters were spread on the surface of Marine Agar plates, further incubated at $+4^{\circ} \mathrm{C}$ for 15 days. Enzymatic measurements of the potential leucine aminopeptidase (LAP), beta-glucosidase (GLU) and alkaline phosphatase (AP) activities - involved in the decomposition of proteins, polysaccharides and organic phosphates respectively - were carried out using a Jenway fluorimeter model 6,280, after addition of increasing concentrations (from 2 to 20 microM) of specific fluorogenic substrates [15].

\section{RESULTS AND DISCUSSION}

Results obtained from the first 'in situ' application in Svalbard Islands indicate that the developed automatic vehicle and water multisampler are good complement of traditional oceanographic cruises, and constitute a practical low-cost system to obtain data with good spatio-temporal resolution both for the initial characterization and for the study of possible natural or anthropogenic disturbance in water quality.

Data concerning bacterial abundance and metabolism, measured on the samples collected through the developed automatic device on June, 23, is reported in Fig. 3.

The counts of the heterotrophic psychrophilic bacteria obtained on Marine agar showed a maximum concentration of $5.65 \times 10^{2} \mathrm{CFU} / \mathrm{mL}$ recorded at station 1 , closest to the glacier, followed by an abrupt decrease to $7.0 \times 10^{1} \mathrm{CFU} / \mathrm{mL}$ (at station 4). Bacterial counts increased again, with a different behavior, moving along the transect (stations 5 to 8 ). 

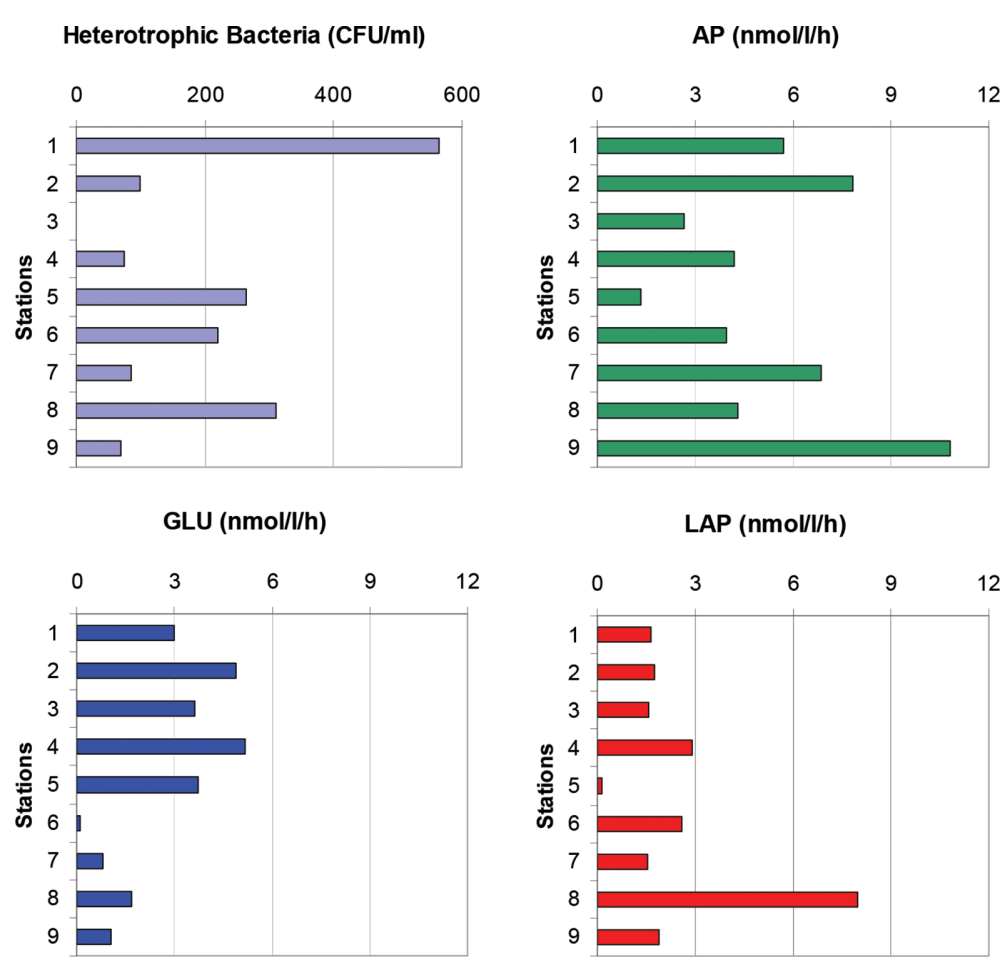

Figure 3: Bacterial abundance and metabolism.

Through their metabolism, microorganisms such as bacteria, fungi and yeasts are the major players in organic matter turnover, being able to attack high molecular weight organic polymers present in the water with the consequent release of nutrients (nitrogen, phosphorus) and carbon that become available for further productive processes [16]. In the study area, enzymatic activity rates were in the order AP> LAP > GLU; on average, their values ranged from 1.33 to $10.81 \mathrm{nmol} / \mathrm{l} / \mathrm{h}$, from 0.15 to $7.97 \mathrm{nmol} / \mathrm{l} / \mathrm{h}$, and from 0.09 to $5.19 \mathrm{nmol} / \mathrm{l} / \mathrm{h}$, respectively. Bacterial metabolism underwent significant spatial changes, with high potential GLU activity at stations close to the glacier until the middle of the transect; LAP showed peaks of activity far from the glacier, while AP levels were not clearly affected by the presence of the glacier.

Spatial variations were significant for Heterotrophic bacteria $(\mathrm{F}=13.20, \mathrm{P}<0.01)$ and at a lesser extent for LAP and GLU ( $\mathrm{F}=4.73$ and 4.48, $\mathrm{P}<0.05$, respectively).

Integrated automatic water quality systems allow the acquisition of a continuous series of samples and related data record, giving the advantage of high data quality and resolution.

The developed systems can find many "in field" applications, which can be summarized in the following points:

- Extreme conditions: long-term series observations are difficult to be performed with high frequency at high latitudes during winter. Automatic samplers are also needed to collect 
samples from large streams and rivers exposed to non-source pollution [17], where manual sampling requires specialized personnel to operated in remote sampling sites or in dangerous locations under adverse weather conditions. In this context, there is a practical application of the multisampler in all the conditions where conventional monitoring sampling cannot be performed, such as in the proximity of glaciers or when the presence of ice blocks may cause difficulties in the pumping phases.

- Eutrophication: toxic algal blooms, with occurrence of red tide phenomena, may take place where water is enriched with massive concentrations of nutrients; toxic compounds are frequently released through the production of aerosol. Sampling under these conditions may result in high risk for the operator's health, therefore remotely-programmable samplers may help face and overcome this problem.

- Wastewater discharges or slurry water: the release of turbid or waste water is a possible field of application, because working with slurry or turbid water may occlude the pipes of the sampler. Moreover, the spatial variability of pollutants may be a subject of concern in assessing environmental risks and developing effective remediation procedures. Particularly for water bodies where water quality fluctuates over relatively short periods of time, collection of single discrete water samples may be thought to be inappropriate for characterizing environmental conditions. In such a case, it seems to be more appropriate to collect composite samples, which are made by a number of high frequency single samples of a given volume over a given period of time pooled together. When rivers affected by pollution are to be sampled, composite sampling is useful alternative to single sampling, made possible through the use of automatic water samplers [18]; this sampling strategy is considered an efficient way of eliminating the effect of diurnal variations in river load strength.

In all the above reported cases, the choice of specific sampling strategies and techniques can affect the analytical results obtained from samples collected in the same area. Automated samplers, which are usually commercially available, are characterized by some basic components, such as programmable operation and memory device, sample collection pump, sample bottles and water level recorder. Frequent maintenance of automated samplers must be performed to limit malfunctions and economic resources must be addressed to this point. The developed system is designed to impose very little additional load on the battery which powers the water sampler, and can operate unattended for short time periods therefore it is ideal for use in small, remote areas.

An important advantage related to the use of the developed equipments is their ability to record natural and episodic events such as storms or blooms, which could otherwise be missed by conventional surveys strategies, for example when research cruises are performed. For example, with the developed water multisampler the frequency of sampling can be modulated/programmed according to research needs, and be changed from a timely fixed sampling to sampling performed during particular conditions only.

Compared to previous water samplers, in past years, automatic samplers or automatic sensors on mooring systems allowed time-series observations of variability in the water biogeochemistry with high sampling frequency [19], enabling the identification of alterations in the biological pump activity caused by meteorological disturbances. Honda and Watanabe [20] developed an automatic water sampler, installed on a mooring system and operating in remote modality, which was able to provide data on the seasonal variability in nutrients and dissolved inorganic Carbon. 


\section{CONCLUSIONS}

The suitability of an automatic multisampler device for the collection and preservation of seawater samples was previously shown [1,2]. In this study a new generation prototype was designed and built to operate in extreme conditions and towed by a USSV to eliminate the risks caused by falling ice blocks in the proximity of glaciers. The Svalbard Archipelago was chosen as a site for testing this prototype for its application, being an area characterized by Atlantic water influx and melting of tidal glaciers which are both linked to climate variability [21]. Changes in arctic microbial communities and carbon processing were predicted to be strictly related to environmental changes [22].

Through this autonomous device, samplings can be programmed, so allowing the acquisition of time-series data on planktonic communities. Due to the possibility to plan the sampling schedule, this device may be particularly useful in studies where dynamics vary on a daily scale. Moreover, thanks to the communication channel made available by the USSV, the operator can also issue commands to the automatic multisampler to take samplings in chosen points of interest.

The results obtained in this study show that the automatic multisampler device is particularly suitable to follow short-term variability in environmental and biological parameters, even at sites which are accessible with difficulty. The determination of microbial abundance and the factors controlling its spatio-temporal variability in glacier ice is a necessary tool to estimate microbial growth and activity, carbon stocks and flows in glacial ecosystems, as well as to predict microbial responses to climate and anthropogenic forcings.

\section{ACKNOWLEDGMENTS}

This study was supported by funds from the National Research Council rewarding project ARCA (DTA.AD001.102.004).

The authors thank Giorgio Bruzzone, Edoardo Spirandelli, Mauro Giacopelli and Arturo Argentieri for their extraordinary contribution to the design, development and exploitation at field of the Shark USSV. The authors also thank Renzo Di Chio, who assembled the water sampler and its electronics, and Roberto Casati of Burkert, the manufacturer of the electrovalves used in the water sampler, who made a substantial rebate on their costs and on the delivery time, so allowing to meet the deadline to ship the instruments to the Svalbard Islands.

\section{REFERENCES}

[1] Zappalà, G., Caruso, G. \& Crisafi, E., An automatic multisampler for bacteriological water quality evaluation: some applications. Geophysical Research Abstracts, 5, 11447, 2003.

[2] Zappalà, G, Caruso, G. \& Crisafi, E., Coastal pollution monitoring by an automatic multisampler coupled with a fluorescent antibody assay. Proceeding of the 5th International Conference on Environmental Problems in Coastal Regions, Coastal Environment V, eds. Brebbia, C.A., Saval Perez, J.M., Garcia-Andion, L \& Villacampa, Y. WIT Press: Southampton, pp. 125-133, 2004.

[3] Caccia, M., Bibuli, M., Bono, R. \& Bruzzone, G., Basic navigation, guidance and control of an unmanned surface vehicle. Autonomous Robots, 25(4), pp. 349-365, 2008. http://dx.doi.org/10.1007/s10514-008-9100-0 
[4] Bibuli, M., Bruzzone, G., Caccia, M. \& Lapierre, L., Path-following algorithms and experiments for an Unmanned Surface Vehicle. Journal of Field Robotics, 26(8), pp. 669-688, 2009.

http://dx.doi.org/10.1002/rob.20303

[5] Zappalà, G., Caruso, G. \& Crisafi, E., The SAM integrated system for coastal monitoring. Proceeding of the 4th International Conference on Environmental Problems in Coastal Regions, Coastal Environment IV, ed. Brebbia, C.A. WIT Press: Southampton, pp. 341-350, 2002.

[6] Zappalà, G., Caruso, G., Azzaro, F. \& Crisafi, E., Integrated environment monitoring from coastal platforms. Proceeding of the Sixth International Conference on the Mediterranean Coastal Environment, ed. Ozhan, E., MEDCOAST, Middle East Technical University: Ankara, 3: pp. 2007-2018, 2003.

[7] Zappalà, G. \& Azzaro, F., A new generation of coastal monitoring platforms. Chemistry and Ecology, 20(5), pp. 387-398, 2004.

http://dx.doi.org/10.1080/02757540410001727990

[8] Zappalà, G., Caruso, G., Azzaro, F. \& Crisafi, E., Multiparametric marine monitoring from automatic coastal platforms. Rapports et procès-verbaux, 37th CIESM Congress, Barcelona (Spain), p. 154, 2004.

[9] Zappalà, G., Caruso, G., Piermattei, V., Bonamano, S., Madonia, A., Di Cicco, A., Martellucci, R. \& Marcelli, M., Integrated marine measurements in Civitavecchia, near Rome. WIT Transactions on Modelling and Simulation, 55, pp. 221-235, 2013.

http://dx.doi.org/10.2495/CMEM130181

[10] Zappalà, G. \& Manzella, G.M.R., An automatic multiple launcher for expendable probes. Proceeding of the 4th International Conference on EuroGOOS European Operational Oceanography: Present and Future, eds. Dahlin, H., Flemming, N.C., Marchand, P., Petersson, S.E., pp. 188-191, 2006. http://dx.doi.org/10.5194/osd-3-997-2006

[11] Zappalà, G., Development of advanced instrumentation for operational oceanography. WIT Transactions on Modelling and Simulation, 46, WIT Press, Southampton, pp. 841-850, 2007.

[12] Zappalà, G., Reseghetti, F. \& Manzella, G.M.R., Development of an automatic multiple launcher for expendable probes. Ocean Sciences, 3, pp. 173-178, 2007, available at: www.ocean-sci.net/3/173/2007/

[13] Zappalà, G., A software set for environment monitoring networks. Proceeding of Envirosoft 2004, Development and Application of Computer Techniques to Environmental Studies X, eds. Latini, G., Passerini, G \& Brebbia, C.A. WIT Press: Southampton, pp. 3-12, 2004.

[14] Zappalà, G., A versatile software-hardware system for environmental data acquisition and transmission. Proceeding Computational Methods and Experimental Measurements $X I V$, eds. Brebbia, C.A \& Carlomagno, G.M. WIT Press: Southampton, pp. 283-294, 2009.

[15] Caruso, G., Leucine aminopeptidase, $\beta$-glucosidase and alkaline phosphatase activity rates and their significance in nutrient cycles in some coastal Mediterranean sites. Marine Drugs, 8(4), pp. 916-940, 2010. http://dx.doi.org/10.3390/md8040916 
[16] Caruso, G., Decembrini, F., Caruso, R., Zappalà, G., Bergamasco, A. \& Leonardi, M., Are microbial enzyme activities suitable indicators of the trophic state of marine ecosystems? In: Pollution Monitoring, eds. Ortiz,A.C \& Griffin, N.B. NOVA Science Publishers, pp. 195-210, 2011.

[17] Harmel R.D., King, K.W. \& Sladee, R.M., Automated storm water sampling on small watersheds. Applied Engineering in Agriculture, 19(6), pp. 667-674, 2003. http://dx.doi.org/10.13031/2013.15662

[18] Facchi, A., Gandolfi, C. \& Whelan, M.J., A comparison of river water quality sampling methodologies under highly variable load conditions. Chemosphere, 66, pp. 746-756, 2007.

http://dx.doi.org/10.1016/j.chemosphere.2006.07.050

[19] Dickey, T., Marra, J., Weller, R., Sigurdson, D., Langdon, C. \& Kinkade, C., Timeseries of bio-optical and physical properties in the Arabian Sea: October 1994-October 1995. Deep-Sea Research II, 45, pp. 2001-2025, 1998. http://dx.doi.org/10.1016/S0967-0645(98)00061-7

[20] Honda, M.C. \& Watanabe, S., Utility of an automatic water sampler to observe seasonal variability in nutrients and DIC in the Northwestern North Pacific. Journal of Oceanography, 63, pp. 349-362, 2007. http://dx.doi.org/10.1007/s10872-007-0034-5

[21] Hop, H., Pearson, T., Nøst Hegseth, E., Kovacs, K.M., Wiencke, C., Kwasniewski, S., et al., The marine ecosystem of Kongsfjorden, Svalbard. Polar Research, 21(1), 167-208, 2002.

http://dx.doi.org/10.1111/j.1751-8369.2002.tb00073.x

[22] Kirchman, D.L., Moran, X.A.G. \& Ducklow, H., Microbial growth in the polar oceans-role of temperature and potential impact of climate change. Nature Reviews of Microbiology, 7, pp. 451-459, 2009.

http://dx.doi.org/10.1038/nrmicro2115 